\title{
Favouritism and financial incentives: A natural experiment*
}

\author{
Neil Rickman \\ University of Surrey \\ and CEPR
}

\author{
Robert Witt \\ University of Surrey
}

October 2, 2006 


\section{Introduction}

A central tenet of principal-agent theory is that a combination of financial rewards and (imperfect) monitoring can be used by principals to incentivise their agents. In particular, the purpose of such instruments is to have the agent (at the expense of some information rent) internalise the principal's preferences when performing his/her tasks. A literature has developed to test the extent to which such incentive contracts perform the roles they are designed for. The key papers here are well summarised in Prendergast (1999) and cover settings as diverse as executive compensation schemes (Murphy (1999)) and the cost of legal aid in England and Wales (Gray et al. (1999)).

Recent work has highlighted an additional source of inefficiency in principalagent relationships: the favouritism that principals can show towards chosen agents. In theory, this can influence numerous economic settings. Thus, Prendergast and Topel (1996) show how favouritism can bias the evaluation of agents' performance in organisations and, in turn, their behaviour. Similarly, large-scale public expenditure decisions can be afflicted by such behaviour: for example, the choice of procurement partner by government departments (Naegelen and Mougeot (1998)) and the regional allocation of public goods in the presence of political bias (Zantman (2002)). In fact, it seems likely that most people will recognise circumstances where favouritism has (or could have) been exercised by principals and this raises the important question of how such behaviour may be controlled. ${ }^{1}$

A potential answer to this question may be to use financial incentives. Such a possibility arises when (as is often the case) the principals favour-

\footnotetext{
1 "Control" of favouritism is a more appropriate objective than its eradication: as Prendergast and Topel (1996) show, to the extent that parties enjoy exercising favouritism, its eradication removes a source of welfare.
} 
ing particular agents are, themselves, agents to a higher principal who may wish to control such behaviour. For example, Prendergast and Topel (1996) model the favouritism exercised by "supervisors" towards "workers" in a manager-supervisor-worker hierarchy. They show that the "managers" can use financial incentives to control supervisors' favouritism. Inspired by this insight, the current paper provides the first test (to our knowledge) of the extent to which financial incentives can help control favouritism in such hierarchical principal-agent settings. In particular, we ask whether a governing body in soccer (the 'higher principal') can influence the favouritism displayed by referees (the 'principals') towards players/teams (the 'agents').

Empirical studies of favouritism in general are limited by the difficult task of its identification but soccer has recently proved a fruitful setting for such analysis. ${ }^{2}$ Garicano et al. (2005) find evidence that soccer referees favour home teams when adjudicating matches. Using data from Spain's top soccer league (the Primera Liga), the authors find that referees add more injury time when the home team is behind in a close game than when it is ahead in a close game (as opposed to those games where the scores are too far apart for additional injury time to make a difference). They attribute this "favouritism" to the social pressure applied by home team supporters. The evident measurability of this favouritism has encouraged several similar studies based on other soccer leagues. Using additional control variables, Sutter and Kocher (2004), Lucey and Power (2004) and Dohmen (2005), all produce a qualitatively similar finding on injury time to Garicano et al. (2005)'s in German, Italian and US soccer leagues respectively. In addition,

\footnotetext{
${ }^{2}$ Favouritism has also received empirical examination in used car markets (Knowles et al. (2001): racial bias) and, indeed, in academic publishing (Medoff (2003): editorial bias). In the context of soccer, the idea that referees may exercise favouritism has gained credibility in the light of recent scandals in Germany, Italy and Brazil; see "The worst scandal of them all", www.news.bbc.co.uk/sport, July 25, 2006.
} 
Sutter and Kocher (2004) and Dohmen (2005) also discover that referees are more inclined to award penalty kicks for the home team as opposed to the away team (see also Nevill et al. (1996)). Finally, Nevill et al. (2002) use a series of controlled experiments with video-taped matches and actual referees to show that crowd noise can influence refereeing decisions. ${ }^{3}$

It is important to consider the mechanisms by which financial incentives might influence referees' decisions. In principle, favouritism can arise through conscious or unconscious responses to crowd pressure. ${ }^{4}$ Garicano et al. (2001) present a model in which referees select their levels of favouritism to maximise a utility function that depends on satisfying home and away fans (the former with a larger weight) and the probability of being reappointed next season (which declines with the soccer authorities' perception of the referees' bias). In this context, additional financial rewards to retaining professional status would (ceteris paribus) alter the referee's marginal conditions for optimal favouritism towards its reduction. Such conscious bias is also modelled in Prendergast and Topel (1996).

Financial incentives may continue to influence favouritism if referees are not so 'calculating', however. This is a point developed in Becker and Murphy (2000), where social influences are acknowledged to affect individual choices in more 'unconscious' ways. This is how Dohmen (2005) interprets

\footnotetext{
${ }^{3}$ The presence of home bias amongst sports referees has received attention from a variety of disciplines (see the surveys in Courneya and Carron (1992) and Nevill and Holder (1999)); while psychologists and health scientists have uncovered a number of potential causes of such behaviour (e.g. Tversky and Kahneman (1974), Wickens and Hollands (2000) and Neave and Wolfson (2003)). More generally, economists have also discussed the interaction between 'social' factors and market outcomes (e.g. Becker and Murphy (2000)).

${ }^{4}$ Apparently, people involved in soccer recognise these possibilities: "[officials] must be sensitive to crowd reactions, they're only human. I used to think they did it on purpose; now I think they just can't avoid it." (Neil Warnock, manager of Sheffield United, on Match of the Day 2, BBC TV, October 23, 2005).
} 
the causes of referee bias. In such settings, Becker and Murphy discuss how financial incentives can operate on socially-influenced preferences: for example, in our context, referees may become more aware of the influence of the crowd on their decisions when considering strategies to help retain their professional status. In this case, financial rewards encourage self-evaluation of performance and produce conformity as referees 'work harder' to control their response to social pressure. ${ }^{5}$ Thus, whether referees' favouritism is viewed as a conscious or unconscious reaction to the social pressures in evidence at a soccer match, it seems reasonable to anticipate that financial incentives may help to check it.

To perform our analysis, we make use of a natural experiment that took place in English soccer in 2001-02. This season saw the introduction of several measures aimed at improving the quality of refereeing in English professional soccer, and these included the introduction of professional referees to the English Premier League. ${ }^{6}$ For the first time, a group of referees was retained for the whole soccer season on a full salary (plus match fees). Along with the intertemporal comparison in performance that this provides, the fact that only the Premier League (in contrast to the leagues below it) introduced this change means that the natural experiment is particularly rare in also containing a cross-sectional dimension.

Like the papers cited above, we first establish the presence of favouritism in our data using Garicano et al. (2005)'s approach: looking for the first

\footnotetext{
${ }^{5}$ Taylor et al. (2005)) provide a broad treatment of these issues. More specifically, Loewenstein and Moore (2004) describe how unconscious self-interest (such as a referee might respond to when in front of a large home crowd) can come into conflict with one's ethical and professional obligations to others. While the operation of self-interest may be "unconscious" and "automatic", understanding these other obligations "often involves a more thoughtful process" (p. 189).

${ }^{6}$ As discussed in Section 2, other measures included organisational changes which, in turn, impacted on referees' training. See NCCFR (2002) for background to the changes.
} 
time at the relationship between injury time and home team match position in close games for English soccer. We discover favouritism similar to (though smaller than) Garicano et al. (2005)'s in the pre-professional English Premier League. However, we find that favouritism disappears in our post-professional Premier League data: this suggests a clear response to the incentives introduced by the policy. ${ }^{7}$ Our results have implications for the multi-million pound worldwide soccer 'industry'. 8 More generally, they also provide empirical support for the use of financial contracts to govern this relatively subtle element of principal-agent behaviour.

We address several possible arguments that could contradict this conclusion. First, it could be argued that we are picking up a 'quality' effect in the sense that the best referees are used in the Premier League and, as such, they are best able to ignore tendencies towards favouritism. Our use of fixed effects controls for this selection bias but does not remove the effect we find from professionalism. Second, it may be that (for whatever reason) the reductions in score-dependent injury time that we find could have happened across English professional soccer in general; again, this would limit the extent to which financial incentives were controlling favouritism. As noted above, we are able to use contemporaneous data from the English First Divi-

\footnotetext{
${ }^{7}$ Of the papers cited earlier, Garicano et al. (2005) are clear that their paper examines only "non-monetary incentives" (p. 11) and this is also true in Sutter and Kocher (2004). Dohmen (2005) uses German data over nine seasons in which he reports increases in the fees paid to referees but he does not seek to identify any relationship between fee rises and levels of bias. In fact, the changes in bias that he does observe are not systematic. Lucey and Power (2004) note smaller levels of bias in Italy than the US and imply that this may be related to the higher financial rewards for referees in the former. Neither of these papers provides a satisfactory basis for examining the role of financial incentives in controlling favouritism: what is needed is an explicit exogenous change in the financial incentives faced by referees such as the one we examine.

${ }^{8}$ The President of soccer's governing body (FIFA), Joseph Blatter, has recently responded to allegations of cheating amongst German soccer referees with the comment that professional referees are "the solution ... once you have a career, and you see it as going to work, then you're not going to cheat." (Kicker, 1 March 2005).
} 
sion (as it was called during our data period) and this allows us to control for such a soccer-wide effect. ${ }^{9}$ Again, our conclusion remains. In addition the cross-sectional component of our data allows us (unlike others) to consider whether our injury time variable is less related to favouritism than to natural asymmetries between the performances of home and away teams: our results suggest that this is not the case. Third, perhaps our results reflect a training effect coming about through superior training of professional referees. Although we cannot directly control for this possibility, we present (in Section 2) several arguments to suggest that differential training and assessment of referees are unlikely to be the principal influence on our results - especially in the two leagues we study.

Last, but by no means least, we consider the question of whether the measure of favouritism used in this paper (and its antecedents) is a suitable one. In particular, a plausible alternative hypothesis might be that teams approach the end of a game in different ways depending on the score. For example, when the home team is behind, it may press harder for an equalising goal and this may lead to more infringements by the away side, or the away team may seek to waste time to protect a valuable away victory. Both of these scenarios could lead to additional injury time being played as a result of the referee seeking to compensate for such behaviour. Clearly, this is an important issue but, also, a potentially elusive one. Nonetheless, our natural experiment allows an interpretation of the results in line with this view. To this extent, therefore, our paper provides an important agenda for future research on the measurement of favouritism.

The paper is structured as follows. The following section provides more

\footnotetext{
${ }^{9}$ Since August 2004, the First Division has been called the Coca Cola Championship but, as our data pre-date this change of name, we refer to it throughout by its previous name.
} 
detail on the switch to professional referees that underlies our natural experiment. Section 3 then presents our data and descriptive statistics before Section 4 sets out and discusses our results. The concluding section discusses our results and suggests extensions to our work.

\section{Professional soccer referees}

Referees (along with two assistants) officiate at all soccer games. Their task is to adjudicate incidents according to rules laid down by the Federation of International Football Associations (FIFA), to apply appropriate sanctions when they deem these rules to have been broken, and to time proceedings so that 90 minutes of play (in two halves of 45 minutes) take place - this will typically require additional time to compensate for stoppages resulting from, say, player injuries, player substitutions and time wasting by the players. During the game, the referee is the sole adjudicator of infringements and exercises considerable discretion when interpreting players' actions and deciding appropriate responses (FIFA (2002)).

Reforms to refereeing in English professional soccer were introduced ahead of the 2001-02 season. These sought to address concerns about the quality of refereeing in all four professional soccer leagues at a time when the game's commercial and media profile was developing rapidly. In particular, it was felt that referees needed a clearer regulatory regime, consistent training, development and monitoring regimes and, for the top games (see below), meaningful financial incentives commensurate with the game's profile. As such, in 2001 the Professional Game Match Officials Board (PGMOB) replaced the National Review Board. Its task was to provide match officials for all professional games played in England, to assess their performance throughout 
the season, and to ensure consistency of training across the leagues. ${ }^{10}$ Officials were divided into two broad groups. First, the Select Group, currently comprising 19 referees and 38 assistant referees, officiate at the top games including all those in the English Premier League. ${ }^{11}$ Second, the National List of officials includes over two hundred individuals as referees and assistant referees who officiate in the remaining professional fixtures.

It should be noted that considerable effort is taken to ensure comparability of the training and assessment methods across Select Group and National List referees: as we have said, training and assessment reforms took place across the leagues. All referees' performances are evaluated from the stands by an independent assessor and referees deemed to have performed poorly face a number of sanctions, the ultimate one being either temporary or permanent removal from their current list, with associated implications for income and status. ${ }^{12}$ In addition it is important that basic training levels are reasonably homogeneous (in particular, between Division 1 and the Premiership). In part, this is to ensure that promotion to the Select Group is possible. For example, on promotion to the Select Group in 2004-05, Mark Clattenburg commented that "the hard work that goes into training referees on the National List means that I am ready to make the step up to the Select Group" (www.premierleague.com). Also, each week, several Select Group referees officiate in Division 1 games and it would be regarded as unacceptable if these games were refereed to a different standard than those elsewhere in the league that week.

\footnotetext{
${ }^{10}$ It should be noted that all referees underwent regular training/fitness assessments and match-by-match performance assessment prior to 2001-02. The new regime built upon this and promoted development and consistency of the programmes.

${ }^{11}$ These referees also officiate at some Football League games and certain FA Cup and League Cup games.

${ }^{12}$ For instance, Select Group referee Andy D'Urso received a 28-day ban in September 2004 for incorrectly sanctioning a player.
} 
The most significant change introduced related to the remuneration of top referees. Prior to the 2001-02 season, referees were employed as amateurs and earned as little as a few hundred pounds per game (plus expenses) - see NCCFR (2002). In contrast, Select Group referees are professional, receiving an annual retainer fee of $£ 33,000$ plus $£ 900$ per game, meaning that a professional referee is virtually certain to earn over $£ 40,000$ in the $2001-02$ season (and subsequently increased). A number of referees continue to work in other professions during the week. ${ }^{13}$

To summarise, soccer referees exercise considerable discretion when officiating games and this may encourage favouritism in their decision making. Top-level referees in England have recently received a significant increase in the remuneration they receive. To the extent that the monitoring and assessment regimes in place provide a credible, and high, opportunity cost to making poor decisions, professionalism might be expected to have reduced scope for favouritism amongst top referees. The remainder of the paper seeks to test this conjecture. We begin by presenting our data.

\section{Data}

At the level of professional soccer players (as opposed to referees), English soccer is divided into four national leagues. We have data from the top two of these: the Premier League (whose referees became professional in 200102) and, below this, the First Division (whose referees remained 'amateur'). The former consists of twenty teams who play each other home and away during a season (yielding a total of 38 matches per team); the latter consists

\footnotetext{
${ }^{13}$ It should be noted that, of the 21 referees officiating in the Premier League in the 1999-00 season, 15 were also refereeing in the 2002-03 professional season.
} 
of twenty-four teams, again playing each other home and away (meaning 46 matches per team in a season). Each season, three teams are relegated from the Premier League to the First Division, with three teams being promoted in the opposite direction and three teams also being relegated from the First Division. Thus, as the season progresses, matches develop added significance.

For every match in these two leagues (for the seasons 1999-00 and 200203), we have data on the goals scored by home and visiting teams, the injury time added by the referee at the end of each half of play, sanctions handed out by referees to players for infringements of the rules ('yellow cards' for moderate infringements and 'red cards' for significant infringements ${ }^{14}$ ), crowd attendance figures and the names of referees who were in charge of each game. These data come from the Press Association. In addition, we also have information on the timing of goals scored in injury time in the Premier League (from Opta Index). Equivalent data are not available for the First Division; instead, goals occurring in or after the final minute of each half are timed at either 45 or 90 minutes. We assume that goals recorded in this way in the First Division are injury time goals. ${ }^{15}$ The data on the remaining variables come from several sources. Player substitutions during each game come from the www.soccerbase.com website. Annual turnover measures for Premier League clubs were gathered from annual balance sheets and profit and loss accounts lodged with Companies House. Table rankings of home teams at the end of the season and ground capacity were collected from

\footnotetext{
${ }^{14}$ Two yellow cards constitute a red card which, in turn, means a player's ejection from the game and his side's numbers being reduced accordingly for the remainder of the game.

${ }^{15}$ Our Opta Index data show that ninety per cent of goals timed at either 45 or 90 minutes in the Premier League in the 1999-00 season were scored during injury time. This compares with 70 per cent in the 2002-03 season. Thus, our assumption for the First Division is likely to be reasonable. It is certainly implausible that most goals timed at 45 or 90 minutes were scored at precisely that time, with only a small number being scored in injury time.
} 
relevant Rothman's Football Yearbooks.

Before proceeding to discuss our results, we explain our choice of seasons for analysis (1999-00 and 2002-03). Clearly, it is important for us that these seasons span the onset of professional Premier League referees (in 2001-02). By not using the seasons immediately before and after the new professional referee era, we aim to avoid potential anticipation effects (in 2000-01) and disequilibrium responses (in 2001-02). Accordingly, we believe our data can help distinguish the 'steady-state' effects of professional referees.

Tables $1 \mathrm{~A}$ and $1 \mathrm{~B}$ provide summary statistics for the variables used in this analysis over the seasons 1999-00 and 2002-03 and in the Premiership and First Division, respectively. The data cover 760 Premier League matches (i.e. 20 teams playing 19 home games in each of two seasons) and 1,104 First Division games (i.e. $24 \times 23 \times 2$ ). Both tables display similar patterns, with a little quantitative difference. Thus, in both leagues, home teams won on average (by nearly half a goal in the Premier League, and just over a third of a goal in the First Division). In both cases, home teams scored roughly 1.5. goals per game, with visitors netting a little over one. Second-half injury time produced more goals for home and away teams in both leagues. In part, this reflected the longer duration of second-half injury time. First Division injury time was longer than in the Premier League, reflecting in part the slightly higher number of player substitutions in that league. Furthermore, home teams scored more goals in both first- and second-half injury time, in both leagues. As might be expected for the higher profile league with larger clubs, Premier League attendances averaged more than twice those in the First Division, with grounds almost 90\% full; First Division grounds were roughly two-thirds full. 


\section{$4 \quad$ Results and interpretations}

\subsection{Results}

The exogenous change of rewards to referees in the Premier League in the 2001-02 season, presents a unique opportunity of testing whether referees respond to financial incentives. In Table 2 we begin our testing for this by using specifications very similar to those used in Garicano et al. (2005). The dependent variable is second half injury time in games where the goal difference is one; i.e. games that are 'close' in the sense that their outcome could be altered by a few more seconds of play. As in Garicano et al. (2005), favouritism is captured by the coefficient on the SCORE DIFFERENCE dummy which is equal to one if the home team is ahead by one goal and zero if the home team is behind by one goal. The estimated coefficient on this dummy reported in column (i) is negative, small in magnitude but strongly significant (i.e. at 1\%). On average, injury time is shorter by 18 seconds, substantially lower than the estimate of 1.88 minutes in Garicano et al. (2005). However, as columns (ii)-(iv) in Table 2 indicate, the presence of additional regressors increases the measure of favouritism to roughly 30 seconds, in each case with strong statistical significance. This should be interpreted as the effect of favouritism (in Garicano et al. (2005)'s terms) on second half injury time in the pre-professional period. ${ }^{16,17}$

\footnotetext{
${ }^{16}$ This additional injury time is lower than that found in Spain and the US. One explanation for this could be that the shorter travel distances in England (and in Germany and Italy, where lower times have also been found) produce a greater preponderance of away team supporters at English games and this exerts a social pressure to counter that postulated by Garicano et al. (2005).

17 As noted in the Introduction, it might be argued that this effect (which we - and others - term 'favouritism') is, in fact, the result of away teams who are a goal ahead experiencing considerable pressure from home teams seeking an equaliser and this may result in additional free-kicks and injury time. We return to this in Section 4.2.
} 
In columns (ii)-(iv) in Table 2 we test for the change in financial rewards of referees by including interaction terms between the YEAR of observation and the SCORE DIFFERENCE dummy. YEAR denotes a dummy variable equal to 1 in the post-professional referee period (2002-03 season) and 0 for games in the pre-professional period (1999-00 season). The interaction term SCORE DIFFERENCE $\times$ YEAR is positive and significant. The estimated coefficients largely offset those on SCORE DIFFERENCE, suggesting that the favouritism of roughly 30 seconds is more-or-less removed after the introduction of professional referees. ${ }^{18}$ This is consistent with the introduction of professional referees generating strong enough financial incentives to influence referees' behaviour. ${ }^{19}$

There are two important concerns with the results discussed above. First, perhaps the highest quality referees are offered professional contracts, in which case, we might simply be picking up a selection bias as opposed to the effects of financial incentives per se. We address this issue by employing referee fixed effects in column (iv) of Table 2. Thus, the results reported

\footnotetext{
${ }^{18}$ Using the column (ii) results, we test for whether the estimate on the SCORE DIFFERENCE $\times$ YEAR interaction term is equal (and of opposite sign) to SCORE DIFFERENCE itself: the resultant $t$-statistic is 0.49 so the null hypothesis is upheld in this case. Thus the effect of favouritism disappears after the introduction of professional referees.

${ }^{19}$ We have considered the robustness of our measure of favouritism in two ways. First, we have looked at whether the 'closeness' of a game matters. For example, we find that the SCORE DIFFERENCE dummy is small and statistically insignificant when there is a two-goal difference in the score at the end of the second half. This finding is consistent with the evidence in Garicano et al. (2005) and contributes to the view that the differences in injury time are related to the prospects that they can alter match outcomes. To investigate further the issue of favouritism, we have also tested whether referees end the game quicker after a home goal is scored in injury time than an away goal. In the Premier league during the 1999-00 and 2002-03 seasons, there were 77 games in which either the home team or the away team scored one goal in second half injury time. We found no evidence to suggest that the amount of injury time depended on who scored. This is in contrast to the findings in Garicano et al. (2005). Second, we have included games that were level at full-time, on the grounds that referees may also seek to protect a home team's single point for a draw. The qualitative nature of our results is not altered by this. (All of these results are available from the authors.)
} 
above ultimately control for potential quality effects.

The second important concern relates to the fact that the professional referee group does not cover other leagues, so that the reduction in favouritism we have found may simply reflect a trend across all of English football. One example might be the training developments that were introduced, across all leagues, at the same time as the Premier League's professional referees; although training programmes existed before, it is possible that developments in 2001 led to a 'training effect' and this is what we have so far picked up. A particular strength of our data is that we are able to use First Division matches as a control group (given that referees here remained amateur but, in other ways - including training,- - were subject to similar developments as Premier League ones) in order to control for such a 'soccer-wide' effect.

Table 3 presents basic statistics on average injury time in games which ended with a one goal difference before and after the introduction of professional referees, across the two football leagues. Looking at Table 3, second half injury time before 2001 was 2.874 minutes in Premier League games, compared with 3.083 minutes for the First Division. After 2001 there was an increase in injury time of 0.41 minutes (2.874 to 3.284 ) for the Premier League. There was a 0.724 increase in minutes for the control group. Taken together, these figures suggest a response of -0.314 minutes. On balance, then, the unconditional difference-in-difference estimates in Table 3 point to a fall in injury time added by referees when professional in the Premier League compared to the control group of the First Division.

Table 4 moves to a regression framework, employing the straightforward differences-in-differences-in-differences specification. The dependent variable is the length of injury time in games that ended with a one goal difference. The PREMIER LEAGUE dummy variable is equal to 1 for games in the 
Premiership and 0 for games in the First Division. Favouritism is again captured by the SCORE DIFFERENCE dummy variable, which equals 1 if the home team is ahead by one goal and 0 if the home team is behind by one goal. Of course, the interpretation of this variable must now recognise that our results involve two football leagues, as well as two periods of time: as such it shows the impact of the score difference on second half injury time in the First Division (i.e. PREMIER LEAGUE is set to zero) in the pre-professional era (YEAR has also been set to zero). Thus, the coefficient on SCORE DIFFERENCE should be interpreted as the effect of Garicano et al. (2005)'s measure of favouritism on second half injury time in the pre-professional period in First Division games. The coefficients of central interest in Table 4 are those on the triple interaction term, PREMIER LEAGUE $\times$ SCORE DIFFERENCE $\times$ YEAR. The coefficient measures the change between the pre- and post-professional referee periods in Premier League compared to First Division second half injury time in games when the home team is leading by one goal.

The results in Table 4 are consistent with the preliminary findings in Table 2. As the coefficients on PREMIER LEAGUE $\times$ SCORE DIFFERENCE show, on average injury time is shorter in the Premiership by roughly 25 seconds when the home team is ahead by one goal. However, the introduction of professional referees had a significant positive effect on second half injury time in the Premier League compared to the First Division. In terms of magnitude, the estimated effect of professional referees on second half injury time in the Premier League compared to First Division is 0.633 in column (i), 0.591 in column (ii) and 0.593 in column (iii) - i.e. something in the order or 35 seconds; these estimates are consistent with favouritism being removed 
after the introduction of professional referees. ${ }^{20}$

\subsection{Interpretations}

The introduction of professional referees created financial rewards for Select Group referees and our results are consistent with these encouraging referees to allocate injury time in a more independent way than was previously the case: in Garicano et al. (2005)'s terms, a reduction in favouritism. This is also consistent with the hypotheses in Prendergast and Topel (1996). Whilst we have controlled for the quality of individual referees and for soccer-wide effects, other interpretations of the results also need consideration. We now turn to these.

One possibility is that the effect we have found results from the superior training of professional referees, as opposed to their desires to retain financial rewards through good performance. While we acknowledge this possibility, we believe that it is unlikely to be the main distinction between the two leagues analysed above. This is because, as noted in Section 2, there are good reasons to believe that training regimes across the two leagues need to foster promotion to the Select Group and comparability when Select Group (and National List) referees are officiating in the same competitions (as happens each week). In addition, both sets of referees are subject to the same independent performance assessment procedures at each game. Given these tendencies towards limited training differentials (and negligible assessment ones), we feel that the principal difference between the two groups of referees relates to income (a guarantee of over $£ 40,000$ in the season we study versus smaller match fees plus expenses). To this extent, it seems reasonable to

\footnotetext{
${ }^{20}$ Note that these results also cast doubt on the alternative hypothesis mentioned in Footnote 17 .
} 
interpret our results in terms of the effects of financial incentives.

Another possibility, alluded to in note 17, questions the measure of favouritism used in this (and previous) papers. In particular, it is possible that the the way in which the game is played depends (at least in part) on the score. Thus, when the home team is behind it may push hard for an equalising goal and the sustained pressure may lead to additional free kicks. Similarly, the away team might waste time in an attempt to protect a valuable away win. Both of these would cause the referee to add more injury time than if the match situation was reversed. On this view, our dependent variable does not measure referees exhibiting favouritism but referees 'doing their jobs'.

Clearly, this is an important critique, not only for our paper but also for related literature. It is also a difficult one to assess empirically because it requires awareness of the pattern of play within any particular game. A number of features of our results are consistent with this view, however. First, the fact that we observe a relatively small injury time differential between the home team being behind or ahead might indicate that referees are not seeking to give realistic opportunities for additional scoring. Second, our finding (in note 19) that the identity of injury time scorers does not alter the time added may also suggest that favouritism is not being exercised. Third, the results in Tables 2 and 4 could be consistent with this alternative hypothesis. This would be the case if it were argued that professional referees are better able to control a game than non-professional ones. We have argued that training may not be the source of this advantage but it is still possible that professionals reflect more carefully on their performance (see note 2) or simply command more respect from players. As such, they may be in better control of games and less likely to face frantic tackling or time wasting as the end approaches. 
As might be expected, these comments suggest that the measurement of favouritism is a delicate task; indeed, it is interesting that our data allow us to consider such subtle effects in a way that previous studies have not been able to. Of course, as noted earlier, others have found larger injury time differentials than our English data exhibit and, also, other indications that apparently suggest favouritism on the part of referees. Further, recent scandals relating to referees and match-fixing in Germany, Italy and Brazil add credibility to this possibility. Nonetheless, it is appropriate to note the issues surrounding whether injury time measures favouritism and to acknowledge that any ambiguity we have uncovered should keep the measurement of favouritism itself at the forefront of research in this area.

\section{Conclusions}

An increasingly popular measure of favouritism has been introduced by Garicano et al. (2005) in the context of soccer. Using this definition, we believe our paper is the first to examine the extent to which such behaviour may be controlled; in our case by financial incentives. The paper's main contribution is to present evidence consistent with such control. We have argued that such financial incentives may be useful either by altering the net marginal benefits from favouritism to a referee who wishes to please the home crowd but does not want to lose professional status, or by encouraging referees to reflect on their performances in such a way as to become aware of the possibilities for favouritism that may arise from social pressure. At the same time, another contribution of the paper is to highlight a potential ambiguity in the interpretation of the measure of favouritism that we adopt. This ambiguity may imply that our results are also consistent with professional referees exercising 
more control over games, but not because they are aiming to help the home side. This is an interesting possibility that clearly merits additional research.

It is worth being clear that, in a multi-million pound high-profile sport like soccer, the performance of referees is of more than academic interest: promotion, relegation, prize money for league placings and players' careers could all be at stake, in principle, if soccer games are not officiated to high standards. Our results are therefore important in indicating that principals may control their agents by appropriate and, in some sense, intuitive means. Of course, this is important in a growing literature that has highlighted the potential for favourisitsm in principal-agent relationships. It also has implications for soccer around the world at a time when senior officials are recommending professional referees as a solution to high profile allegations of referees' cheating (see note 8).

An interesting question raised by our results is the extent to which professional referees have increased welfare in English soccer. Of course, to the extent that home teams now receive less 'favours' from referees, we have not identified a Pareto improving policy. However, one might argue that some of the costs of tackling favouritism identified by Prendergast and Topel (1996) are not present in our setting. In particular, because referees negotiated the professional package before signing up to it, a revealed preference argument might suggest that they have been compensated for the loss of welfare associated with being less able to exercise discretion. If so, then the wider benefits of impartiality and objectivity that we have identified might be said to imply a positive welfare effect from professional referees.

We note that our results could be further strengthened by data on referees' earnings outside football (which would influence the opportunity cost of being removed from the professional referees' list) and on referees' individ- 
ual characteristics. Perhaps understandably, referees and their professional association, are protective of such data and we have (so far) been unable to generate consistent observations for such controls. In addition, in order to distinguish more clearly between the two interpretations of Garicano et al. (2005)'s measure of favouritism, it would be necessary to have more detail on activity that takes place during a soccer game. Such data are difficult to come by but would add a valuable dimension to an already important, and interesting, research agenda.

\section{References}

Becker, G. S. and Murphy, K. J. (2000). Social Economics: Market Behaviour in a Social Environment. Harvard University Press, Cambridge, MA.

Courneya, K. S. and Carron, A. V. (1992). The home advantage in sport competitions: A literature review. Journal of Sport and Exercise Psychology, 14, 13-27.

Dohmen, T. J. (2005). Social pressure influences decisions of individuals: Evidence from the behaviour of football referees. IZA Discussion Paper 1595, Institute for the Study of Labour, Bonn.

FIFA (2002). Laws of the Game. Fèderation Internationale de Football Association, Zurich, Switzerland.

Garicano, L., Palacios-Huerta, I., and Prendergast, C. (2001). Favouristism under social pressure. NBER Working Paper 8376, National Bureau of Economic Research, Cambridge MA. 
Garicano, L., Palacios-Huerta, I., and Prendergast, C. (2005). Favouristism under social pressure. Review of Economics and Statistics, 87(2), 208-216.

Gray, A., Rickman, N., and Fenn, P. (1999). Professional autonomy and the cost of legal aid. Oxford Economic Papers, 51(3), 545-558.

Knowles, J., Persico, N., and Todd, P. (2001). Racial bias in motor vehicle searches: Theory and evidence. Journal of Political Economy, 109, 203229.

Loewenstein, G. and Moore, D. A. (2004). Self-interest, automaticity, and the psychology of conflict of interest. Social Justice Research, 17(2), 189-202.

Lucey, B. M. and Power, D. (2004). Do soccer referees display home team favouritism? Working Paper, School of Business Studies and Institute for International Integration Studies, Trinity College, Dublin.

Medoff, M. H. (2003). Editorial favouritism in economics? Southern Economic Journal, 70(2), 425-434.

Murphy, K. J. (1999). Executive compensation. In O. C. Ashenfelter and D. Card, editors, Handbook of Labour Economics, volume 3(2), pages 24852563. Elsevier North-Holland, Amsterdam.

Naegelen, F. and Mougeot, M. (1998). Discriminatory public procurement and cost reduction incentives. Journal of Public Economics, 67(3), 349367.

NCCFR (2002). Refereeing. Fact Sheet No. 15, Sir Norman Chester Centre for Football Research, University of Leicester.

Neave, N. and Wolfson, S. (2003). Testosterone, territoriality and the home advantage in soccer. Psychology and Behaviour, 78, 269-275. 
Nevill, A. M. and Holder, R. L. (1999). Home advantage in sport. an overview of studies on the advantage of playing at home. Sports Medicine, 28, 221236.

Nevill, A. M., Newell, S. M., and Gale, S. (1996). Factors associated with home advantage in English and Scottish soccer matches. Journal of Sports Science, 14, 181-186.

Nevill, A. M., Balmer, N. J., and Williams, A. M. (2002). The influence of crowd noise and experience upon refereeing decisions in football. Psychology of Sport and Exercise, 3, 261-272.

Prendergast, C. (1999). The provision of incentives in firms. Journal of Economic Literature, 37, 7-63.

Prendergast, C. and Topel, R. (1996). Favouritism in organisations. Journal of Political Economy, 104(5), 958-979.

Sutter, M. and Kocher, M. G. (2004). Favouritism of agents - the case of referees' home bias. Journal of Economic Psychology, 25, 461-469.

Taylor, S. E., Peplau, L. A., and Sears, D. O. (2005). Social Psychology. Pearson Prentice Hall, London, twelfth edition.

Tversky, A. and Kahneman, D. (1974). Judgement under uncertainty: Heuristics and biases. Science, 185, 1124-1131.

Wickens, C. D. and Hollands, J. G. (2000). Engineering Psychology and Human Preference. Prentice Hall, Englewood Cliffs, NJ, third edition.

Zantman, W. (2002). Constitutional design and regional favouritism. Journal of Public Economic Theory, 4(1), 71-93. 
Table 1A: Descriptive Statistics for the Premier League Sample

\begin{tabular}{|l|c|c|c|c|c|}
\hline \multicolumn{1}{|c|}{ Variable } & Obs. & Mean & $\begin{array}{c}\text { Standard } \\
\text { Deviation }\end{array}$ & Min & Max \\
\hline Score difference & 760 & 0.461 & 1.721 & -6 & 8 \\
\hline Score home & 760 & 1.586 & 1.289 & 0 & 8 \\
\hline Score visitor & 760 & 1.125 & 1.098 & 0 & 6 \\
\hline $\begin{array}{l}\text { Goals scored in injury } \\
\text { time } 1^{\text {st }} \text { half home }\end{array}$ & 760 & 0.036 & 0.185 & 0 & 1 \\
\hline $\begin{array}{l}\text { Goals scored in injury } \\
\text { time 2 } 2^{\text {nd }} \text { half home }\end{array}$ & 760 & 0.068 & 0.258 & 0 & 2 \\
\hline $\begin{array}{l}\text { Goals scored in injury } \\
\text { time } 1^{\text {st }} \text { half visitor }\end{array}$ & 760 & 0.015 & 0.119 & 0 & 1 \\
\hline $\begin{array}{l}\text { Goals scored in injury } \\
\text { time 2nd half visitor }\end{array}$ & 760 & 0.041 & 0.198 & 0 & 1 \\
\hline $\begin{array}{l}\text { Minutes injury time } 1^{\text {st }} \\
\text { half }\end{array}$ & 760 & 1.796 & 1.022 & 0 & 14 \\
\hline $\begin{array}{l}\text { Minutes injury time 2 } \\
\text { half }\end{array}$ & 760 & 2.822 & 1.050 & 0 & 9 \\
\hline Yellow cards home & 760 & 1.393 & 1.207 & 0 & 5 \\
\hline Yellow cards visitor & 760 & 1.838 & 1.352 & 0 & 7 \\
\hline Red cards home & 760 & 0.063 & 0.259 & 0 & 2 \\
\hline Red cards visitor & 760 & 0.120 & 0.337 & 0 & 2 \\
\hline $\begin{array}{l}\text { Total player } \\
\text { substitutions }\end{array}$ & 760 & 3.993 & 1.303 & 0 & 6 \\
\hline Attendance (000’s) & 760 & 33.114 & 11.099 & 8.248 & 67.721 \\
\hline Attendance/Capacity & 760 & 0.896 & 0.119 & 0.314 & 1.038 \\
\hline & & & & & \\
\hline
\end{tabular}

Note: A maximum value for attendance/capacity greater than one is due either to a combination of heterogeneous data sources or to ground improvements over the season. In fact, Southampton and Watford are the only teams in our Premier League data with reported attendances at some games greater than the ground capacity. 
Table 1B: Descriptive Statistics for the First Division Sample

\begin{tabular}{|l|c|c|c|c|c|}
\hline \multicolumn{1}{|c|}{ Variable } & Obs. & Mean & $\begin{array}{c}\text { Standard } \\
\text { Deviation }\end{array}$ & Min & Max \\
\hline Score difference & 1104 & 0.389 & 1.637 & -6 & 6 \\
\hline Score home & 1104 & 1.509 & 1.222 & 0 & 7 \\
\hline Score visitor & 1104 & 1.120 & 1.114 & 0 & 7 \\
\hline $\begin{array}{l}\text { Goals scored in injury } \\
\text { time } 1^{\text {st }} \text { half home }\end{array}$ & 1104 & 0.058 & 0.238 & 0 & 2 \\
\hline $\begin{array}{l}\text { Goals scored in injury } \\
\text { time 2 } 2^{\text {nd }} \text { half home }\end{array}$ & 1104 & 0.075 & 0.267 & 0 & 2 \\
\hline $\begin{array}{l}\text { Goals scored in injury } \\
\text { time } 1^{\text {st }} \text { half visitor }\end{array}$ & 1104 & 0.039 & 0.194 & 0 & 1 \\
\hline $\begin{array}{l}\text { Goals scored in injury } \\
\text { time 2nd half visitor }\end{array}$ & 1104 & 0.050 & 0.218 & 0 & 1 \\
\hline $\begin{array}{l}\text { Minutes injury time } 1^{\text {st }} \\
\text { half }\end{array}$ & 1104 & 2.233 & 1.189 & 0 & 14 \\
\hline $\begin{array}{l}\text { Minutes injury time 2 } \\
\text { half }\end{array}$ & 1104 & 3.203 & 1.187 & 0 & 10 \\
\hline Yellow cards home & 1104 & 1.151 & 1.122 & 0 & 7 \\
\hline Yellow cards visitor & 1104 & 1.647 & 1.295 & 0 & 7 \\
\hline Red cards home & 1104 & 0.066 & 0.273 & 0 & 2 \\
\hline Red cards visitor & 1104 & 0.119 & 0.363 & 0 & 2 \\
\hline $\begin{array}{l}\text { Total player } \\
\text { substitutions }\end{array}$ & 1104 & 4.024 & 1.273 & 0 & 6 \\
\hline Attendance (000's) & 1104 & 14.793 & 7.093 & 0.849 & 33.027 \\
\hline Attendance/Capacity & 1104 & 0.655 & 0.202 & 0.032 & 1.047 \\
\hline & & & & & \\
\hline
\end{tabular}

Note: A maximum value for attendance/capacity greater than one is due either to a combination of heterogeneous data sources or to ground improvements over the season. In fact, Portsmouth, Walsall, Crewe and Fulham are the only teams in our First Division data with reported attendances at some games greater than the ground capacity. 
Table 2: Score difference and Year Interactions

\begin{tabular}{|l|c|c|c|c|}
\hline Independent variable & (i) & (ii) & (iii) & (iv) \\
\hline & & & & \\
\hline Constant & $3.251^{* * *}$ & $3.172^{* * *}$ & $2.248^{* * *}$ & 2.290 \\
& $(0.091)$ & $(0.126)$ & $(0.207)$ & $(1.935)$ \\
\hline Score difference & $-0.300^{* * *}$ & $-0.516^{* * *}$ & $-0.503^{* * *}$ & $-0.531^{* * *}$ \\
& $(0.120)$ & $(0.166)$ & $(0.159)$ & $(0.191)$ \\
\hline Year & & 0.159 & 0.079 & 0.214 \\
& & $(0.178)$ & $(0.172)$ & $(0.419)$ \\
\hline Score difference $\times$ Year & & $0.435^{*}$ & $0.398^{*}$ & $0.456^{*}$ \\
& & $(0.235)$ & $(0.226)$ & $(0.263)$ \\
\hline Yellow cards & & & $0.092^{* * *}$ & $0.106^{* *}$ \\
& & & $(0.037)$ & $(0.044)$ \\
\hline Red cards & & & -0.012 & -0.044 \\
& & & $0.132)$ & $(0.152)$ \\
\hline Player substitutions & & & $(0.044)$ & $(0.054)$ \\
\hline & & No & No & Yes \\
\hline Referee Fixed effects & No & No & No & Yes \\
\hline Team Fixed effects & No & & & \\
\hline & & 0.06 & 0.15 & 0.32 \\
\hline $\mathrm{R}^{2}$ & 0.02 & 311 & 311 & 311 \\
\hline Observations & 311 & & \\
\hline & & & & \\
\hline
\end{tabular}

Notes: The dependent variable is the length of injury time in games that ended with a 1 goal difference. Score difference is equal to 1 if the home team is ahead by 1 goal before injury time begins, and 0 if it is behind by 1 goal. ***, ** and * denotes statistical significance at the 1 per cent, 5 per cent and 10 per cent levels respectively. Standard errors are in parentheses. The regression in column (iv) include controls for turnover of clubs, table rankings of home teams, the absolute value of the difference in ranks, attendance, ratio of attendance to capacity and monthly dummies. 
Table 3: Second half injury time

\begin{tabular}{|l|c|c|c|}
\hline & $\begin{array}{l}\text { Pre-Professional } \\
\text { Referee Period }\end{array}$ & $\begin{array}{l}\text { Post-Professional } \\
\text { Referee Period }\end{array}$ & Difference \\
\hline & & & $0.410^{* * *}$ \\
\hline Premier League & 2.874 & 3.284 & $(0.117)$ \\
\hline First Division & $(0.095)$ & $(0.069)$ & $0.724^{* * *}$ \\
& $(0.072)$ & 3.806 & $(0.108)$ \\
\hline Difference-in- & & $(0.081)$ & $-0.314^{* *}$ \\
Difference & & & $(0.159)$ \\
\hline & & & \\
\hline
\end{tabular}

Notes: The sample includes games in which the second half ended with a 1 goal difference before injury time begins. $* * *$ and $* *$ denotes statistical significance at the 1 per cent and 5 per cent levels respectively. Standard errors are in parentheses. Pre-professional period is the 1999-00 season. Postprofessional period defined as the 2002-03 season. 
Table 4: Score difference, Year and League Interactions

\begin{tabular}{|l|l|l|l|}
\hline Independent variable & \multicolumn{1}{|c|}{ (i) } & \multicolumn{1}{|c|}{ (ii) } & \multicolumn{1}{c|}{ (iii) } \\
\hline & & & \\
\hline Premier League & 0.245 & 0.202 & -0.107 \\
& $(0.214)$ & $(0.223)$ & $(0.301)$ \\
\hline Score difference & -0.097 & -0.140 & -0.166 \\
& $(0.156)$ & $(0.154)$ & $(0.161)$ \\
\hline Year & $0.834^{* * *}$ & $0.761^{* * *}$ & $0.625^{* * *}$ \\
& $(0.182)$ & $(0.178)$ & $(0.244)$ \\
\hline Premier League $\times$ Score difference & $-0.417^{*}$ & $-0.387^{*}$ & -0.349 \\
& $(0.235)$ & $(0.229)$ & $(0.238)$ \\
\hline Premier League $\times$ Year & $-0.654^{* * *}$ & $-0.686^{* * *}$ & -0.560 \\
& $(0.266)$ & $(0.260)$ & $(0.361)$ \\
\hline Score difference $\times$ Year & -0.233 & -0.249 & -0.208 \\
& $(0.221)$ & $(0.215)$ & $(0.222)$ \\
\hline Premier League $\times$ Score difference $\times$ Year & $0.633^{* *}$ & $0.591^{*}$ & $0.593^{*}$ \\
& $(0.332)$ & $(0.324)$ & $(0.336)$ \\
\hline & & & \\
\hline & & & \\
\hline Referee Fixed Effects & Yes & Yes & Yes \\
\hline Team Fixed Effects & No & No & Yes \\
\hline & & & \\
\hline $\mathrm{R}^{2}$ & 0.29 & 0.33 & 0.38 \\
\hline Observations & 763 & 763 & 763 \\
\hline & & & \\
\hline
\end{tabular}

Notes: The dependent variable is the length of injury time in games that ended with a 1 goal difference. Score difference is equal to 1 if the home team is ahead by 1 goal before injury time begins, and 0 if it is behind by 1 goal. ***, ** and * denotes statistical significance at the 1 per cent, 5 per cent and 10 per cent levels respectively. Standard errors are in parentheses. The regressions in columns (ii) and (iii) include controls for yellow cards, red cards, substitutions, table rankings of home teams, the absolute value of the difference in ranks, and attendance. 